\title{
Correction to: Autologous Versus Alloplastic Reconstruction for Patients with Obesity: A Systematic Review and Meta-analysis
}

\author{
Rawan ElAbd ${ }^{1}$ Neetin Prabhu ${ }^{2} \cdot$ Alaa Alibrahim $^{2} \cdot$ Emily Burke $^{2} \cdot$ \\ Jason Williams ${ }^{2} \cdot$ Osama Samargandi $^{3,4}$ (i)
}

Published online: 24 February 2022

(C) Springer Science+Business Media, LLC, part of Springer Nature and International Society of Aesthetic Plastic Surgery 2022

\section{Correction to: Aesth Plast Surg https://doi.org/10.} 1007/s00266-021-02664-y

This article was updated to replace low resolution images and table 3 .
Publisher's Note Springer Nature remains neutral with regard to jurisdictional claims in published maps and institutional affiliations.

The original article can be found online at https://doi.org/10.1007/ s00266-021-02664-y.

Osama Samargandi

Osamargandi@dal.ca

1 Department of Surgery, Faculty of Medicine, Kuwait University, Kuwait City, Kuwait

2 Division of Plastic Surgery, Faculty of Medicine, Dalhousie University, Halifax, Canada

3 Okanagan Plastic Surgery Center \&, Kelowna General Hospital, University of British Columbia, Okanagan Campus, Kelowna, British Columbia, Canada

4 Department of Surgery, King Abdulaziz University, Jeddah, Saudi Arabia 